\title{
Correction to: Cell communication and signaling: how to turn bad language into positive one
}

\author{
Claudia Chiodoni ${ }^{1 *}$, Maria Teresa Di Martino ${ }^{2}$, Francesca Zazzeroni ${ }^{3}$, Michele Caraglia ${ }^{4}$, Massimo Donadelli ${ }^{5}$, \\ Stefania Meschini ${ }^{6}$, Carlo Leonetti ${ }^{7}$ and Katia Scotlandi $i^{*}$
}

\section{Correction to: J Exp Clin Cancer Res https://doi.org/10.1186/s13046-019-1122-2}

In the original publication of this article, [1] the affiliation for Katia Scotlandi needs to be revised, because the author prefers using its Italian name: Experimental Oncology Lab, CRS Development of Biomolecular Therapies, IRCCS Istituto Ortopedico Rizzoli. We apologize for any confusion this may have caused.

\footnotetext{
Author details

'Molecular Immunology Unit, Department of Research, Fondazione IRCCS Istituto Nazionale dei Tumori, Milan, Italy. ${ }^{2}$ Department of Experimental and Clinical Medicine, University of Catanzaro "Magna Graecia", Catanzaro, Italy. ${ }^{3}$ Department of Biotechnological and Applied Clinical Sciences, University of L'Aquila, L'Aquila, Italy. ${ }^{4}$ Department of Biochemistry, Biophysics and General Pathology, University of Campania "L. Vanvitelli", Naples, Italy. ${ }^{5}$ Department of Neurosciences, Biomedicine and Movement Sciences, Section of Biochemistry, University of Verona, Verona, Italy. ${ }^{6}$ National Center for Drug Research and Evaluation, National Institute of Health, Rome, Italy. ${ }^{7}$ UOSD SAFU, IRCCS-Regina Elena National Cancer Institute, Rome, Italy. ${ }^{8}$ Experimental Oncology Lab, CRS Development of Biomolecular Therapies, IRCCS Istituto Ortopedico Rizzoli, Bologna, Italy.
}

Published online: 25 October 2019

\section{Reference}

1. Chiodoni, et al. Cell communication and signaling: how to turn bad language into positive one. J Exp Clin Cancer Res. 2019;38:128. https://doi. org/10.1186/s13046-019-1122-2.

\footnotetext{
* Correspondence: claudia.chiodoni@istitutotumori.mi.it; katia.scotlandi@ior.it ${ }^{1}$ Molecular Immunology Unit, Department of Research, Fondazione IRCCS Istituto Nazionale dei Tumori, Milan, Italy

${ }^{8}$ Experimental Oncology Lab, CRS Development of Biomolecular Therapies, IRCCS Istituto Ortopedico Rizzoli, Bologna, Italy

Full list of author information is available at the end of the article
}

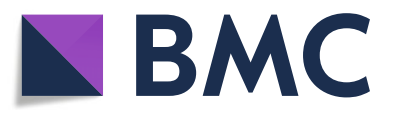

(c) The Author(s). 2019 Open Access This article is distributed under the terms of the Creative Commons Attribution 4.0 International License (http://creativecommons.org/licenses/by/4.0/), which permits unrestricted use, distribution, and reproduction in any medium, provided you give appropriate credit to the original author(s) and the source, provide a link to the Creative Commons license, and indicate if changes were made. The Creative Commons Public Domain Dedication waiver (http://creativecommons.org/publicdomain/zero/1.0/) applies to the data made available in this article, unless otherwise stated. 